\title{
AÇÃO DA CAFEÍNA NO DESENVOLVIMENTO EMBRIONÁRIO E NA LACTAÇÃO. ESTUDO EXPERIMENTAL EM RATOS.
}

\author{
Ana Rosa Crisci \\ Mestre em Bioengenharia / Centro Universitário Barão de Mauá / Ribeirão Preto / SP \\ criscicozac@netsite.com.br \\ Gisele Carolina Bianchi \\ Enfermeira/ Centro Universitário Barão de Mauá / Ribeirão Preto / SP \\ bianchi_gisele89@live.com \\ Alessandra Rossi Marchioni \\ Enfermeira/ Centro Universitário Barão de Mauá / Ribeirão Preto / SP \\ leka_show2@hotmail.com \\ Amelina Toquetti Zanetti \\ Enfermeira/ Centro Universitário Barão de Mauá / Ribeirão Preto / SP \\ mel_toquetti@hotmail.com \\ Larissa Mara de Melo Guedes Araújo \\ Enfermeira/ Centro Universitário Barão de Mauá / Ribeirão Preto / SP \\ lalaguedes@hotmail.com
}

Recebido: 12 de março de 2013. Revisado: 24 de maio de 2013. Aceito: 12 de setembro de 2013.

Publicado online: 03 de outubro de 2013.

\section{Resumo}

O hábito de consumir café e outros alimentos que contém cafeína é muito difundido em todo o mundo e embora os efeitos nocivos desta substância no corpo humano sejam amplamente conhecidos, principalmente sobre o sistema neurológico, seu consumo não diminui nem mesmo em situações especiais como, por exemplo, na gravidez. Diante desta afirmação, resolveu se realizar este estudo com o objetivo de avaliar os efeitos do consumo excessivo de cafeína durante a gestação e lactação. Nesta investigação foram utilizadas seis ratas prenhas, que foram divididas em três grupos com duas ratas em cada grupo. Cada grupo foi formado por 2 ratas que denominamos de controle só ingerindo água e tratada ingerindo cafeína na água. A dosagem dessa cafeína foi de $21,5 \mathrm{mg} / 1000 \mathrm{~g}$ de peso do animal. As variáveis avaliadas foram: massa corporal dos filhotes ao nascer e durante todo o período de amamentação, massa relativa do fígado e pulmão dos filhotes após o nascimento, aos 14 e 21 dias de amamentação, o número de filhotes de cada grupo, o comprimento desses filhotes e qualquer anomalia detectada macroscopicamente. Foram avaliados histologicamente o fígado e o pulmão dos animais sacrificados ao nascer e aos $14^{\circ}$ e $21^{\circ}$ dias de amamentação de ambos os grupos, controle e tratado. Os dados obtidos das variáveis analisadas foram avaliados estatisticamente utilizando o teste não paramétrico Mann-Whitney. Os resultados obtidos demonstraram o número de filhotes dos grupos tratados foi menor, assim como o seu comprimento. Em relação aos órgãos também foi constatado uma diminuição da massa relativa, e na histopatologia do fígado encontrou-se uma megalocitose, vacúolos citoplasmáticos e uma dilatação de vasos entre os hepatócitos; no 
pulmão observou-se um espessamento de septos interalveolares e um infiltrado inflamatório, esses achados no grupo controle não foram encontrados ou considerados relevantes. Concluímos que nossos resultados possam contribuir para que o profissional de enfermagem extrapolando para humanos possa orientar melhor suas pacientes gestantes, lactantes e neonatos, no que se refere a alimentos e drogas que contém cafeína.

Palavras-chave: cafeína; gestantes; lactantes

\begin{abstract}
Coffee drinking and consuming products containing caffeine is widespread around the world and even though the harmful effects of this substance on the human body and principally on the neurological system are well known its consumption does not seem to diminish even in special circumstances like, for example, pregnancy. As a result of this affirmation, it was decided to study the effects of caffeine consumption during pregnancy and lactation. For this investigation six pregnant rats were used, that were divided into three groups. Each group was composed of two rats, one of which was the control and received only water, the other was treated by ingesting caffeine $21.5 \mathrm{mg} / 1000 \mathrm{~g}$ of animal weight in water. The evaluated variables were: body mass of the new born rats and during breast feeding, relative liver and lung mass of the baby rats at birth, at 14 and 21 days of breast feeding, the number of babies born in each group, the length of the bay rats and any anomaly detected macroscopically. The liver and lungs of the animals of both the control and treated groups were evaluated histologically at intervals beginning with those sacrificed at birth, 14 and 21 days of breast feeding. The data obtained from the variables were evaluated estatistically using the MannWhitney non parametric test. The obtained results showed that the number of babies in the treated groups was less, as was their length also. In relation to the internal organs it was also confirmed that there was a reduction in the relative mass, and changes in the histopathology examination of the liver. Megalocytosis was observed as well as cytoplasmatic vacuoles and dilated vessels between the hepatocytes.In the lungs, thickening or the septum intraveolar and an inflammatory infiltrate was seen, these findings in the control group were not found or considered to be relevant. It was concluded that these results can contribute towards increasing the knowledge of professional nurses in regards to the effects of caffeine on the foetus and breast feeding infant. In this way helping to advocate for caffeine abstinence during pregnancy and breast feeding and offering these woman an ample list of food products and medications to avoid because of their caffeine content.
\end{abstract}

Keywords: caffeine; pregnancy; breast feeding.

\title{
1. INTRODUÇÃO
}

O hábito de consumir café, chá, refrigerante e chocolates é muito grande em todo o mundo, esses alimentos constituem a maior fonte de cafeína da nossa alimentação. Sendo assim, muitas pesquisas tem se desenvolvido com o objetivo de conhecer os seus efeitos no desenvolvimento embrionário e na lactação (BICALHO, 2002).

Esse interesse teve inicio na década de 70 quando estudos com animais comprovaram que a cafeína em excesso atuava na diminuição do crescimento e redução do peso de recém-nascidos (CHAVES e LAMONIER 2004). Não há porém, um consenso, alguns consideram que isto só ocorre se for associado a outros hábitos como, fumar e ingerir bebidas alcoólicas (BICALHO,2002), o uso da cafeína parece influenciar, também, o padrão de consumo de cocaína e anfetaminas, aumentando a vulnerabilidade ao abuso destes psicoestimulantes (BUDNEY, 1993; KOZLOWSKI et al., 1993).

A cafeína é uma droga que causa dependência física e psicológica. Ela opera por mecanismos similares às anfetaminas e à cocaína . Seus efeitos, entretanto, são mais fracos do que estas drogas, mas ela age nos mesmos receptores do sistema nervoso central ( STRAIN e GRIFFTHS, 2000). 
Acredita- se que a ação estimulante da cafeína no SNC envolve a estimulação do sistema nervoso simpático, aumentando a liberação e, conseqüentemente, a ação das catecolaminas, particularmente a epinefrina (RACHIMA-MAOZ, PELEG e ROSENTHAL, 1998; YAMADA, NAKAZATO, OHGA, 1989).

Segundo Spriet (1995), a cafeína tem efeitos ergogênicos durante o exercício físico, atua aumentando os ácidos graxos livres nos tecidos e nos estoques intramusculares.

Outra possibilidade que justifica o efeito ergogênico da cafeína são as suas ações em co-produtos do músculo esquelético, alterando íons, particularmente sódio e potássio; inibindo a fosfodiesterase (PDE), possibilitando um aumento na concentração de adenosina monofosfato cíclica (AMPc); efeito direto sobre a regulação metabólica de enzimas semelhantes às fosforilases (PHOS); e aumento na mobilização de cálcio através do retículo sarcoplasmático, o qual contribui para o potencialização da contração muscular (SINCLAIR e GEIGER, 2000).

Entretanto a popularidade da cafeína é como droga psicoativa, isso deve-se às suas propriedades estimulantes, que dependem da sua habilidade de diminuir a transmissão de adenosina no cérebro ( FISONE et al, 2004).

Sendo a cafeína semelhante à adenosina, liga-se com facilidade aos receptores da adenosina porém não tem a mesma atividade, não diminui a atividade do SNC e não provoca vasodilatação, ao contrário, a cafeína causa a constrição dos vasos sanguíneos da cabeça, pois bloqueia a ação dilatadora da adenosina( MANDEL,2002).

A ligação da adenosina, um neurotransmissor natural, aos seus receptores, diminui a atividade neural, dilata os vasos sanguíneos, entre outros. A cafeína se liga aos receptores da adenosina e impede a ação da mesma sobre o SNC. A cafeína, portanto, estimula a atividade neural e causa a constrição dos vasos sanguíneos, pois bloqueia a ação da adenosina (STRAIN e GRIFFTHS, 2000).

Segundo o mesmo autor, através da vasoconstrição há um aumento das catecolaminas, que influenciam no desenvolvimento da placenta, diminuindo os suprimentos fetais de oxigênio, e consequentemente uma diminuição do peso fetal, malformação fetal, podendo evoluir para hipóxia e morte fetal.

De acordo com Souza e Sichieri (2005), a cafeína atravessa facilmente as barreiras placentárias, que passará pra o líquido amniótico, sangue do cordão umbilical, plasma e urina dos neonatos, o que pode diminuir o crescimento intra uterino fetal e reduzirem o peso ao nascer, reabsorção fetal e teratogênese, além disso, existem milhares de drogas prescritas e não prescritas que contêm cafeína e estas por sua vez podem ser usadas na gravidez.

A cafeína é rapidamente absorvida a partir das vias orais, retal ou pariental 50 a 75 minutos após ingestão oral e registram-se as concentrações plasmáticas máxima de cafeína. (PENILDON,2010).

Segundo Ricci (2008), anomalias congênitas não foram associadas ao consumo de cafeína, mas o consumo materno de café diminui a absorção de ferro e pode aumentar o risco de anemia durante a gravidez, ocorrem os efeitos de vasoconstrição e diurese leve na mãe; estimulação fetal, porém efeitos teratogênicos não foram documentados nas pesquisas.

Diante do exposto entende- se a necessidade de mais investigações com a finalidade de avaliar os efeitos do consumo excessivo da cafeína em gestantes, lactantes e neonatos. Desta maneira resolveu-se realizar uma investigação experimental em ratos Wistar com o objetivo de identificar a ação da cafeína no desenvolvimento embrionário e na lactação. 
Com o intuito de verificar o ganho de massa relativa das mães durante o período gestacional e de lactação; a massa corporal dos recém-nascidos e dos sacrificados aos 14 e 21 dias após o nascimento; a massa relativa de alguns órgãos dos filhotes após o sacrifício dos mesmos; assim como a histopatologia do pulmão e do fígado .

\section{MATERIAL E MÉTODOS}

No presente estudo foram utilizadas 6 ratas, da linhagem Wistar, cujos pesos variaram entre 250 a 300g. Os animais foram mantidos no biotério, em gaiolas individuais, em condições controladas de temperatura e em regime de luz de $12 \mathrm{~h} / 12 \mathrm{hs}$, até o acasalamento.

Para o acasalamento foram colocadas 2 fêmeas nuligestas na gaiola de cada macho, por um período correspondente a três horas por dia.

O início da gestação foi confirmado através de exame físico e laboratorial feito por profissional especializado, após a confirmação da prenhez, as fêmeas foram separadas em gaiolas individuais compondo os seguintes grupos: o grupo 1: composto por duas ratas prenhes, sendo que uma delas tomou água e a outra $100 \mathrm{ml}$ de água com $21,5 \mathrm{mg} / \mathrm{kg}$ de cafeína (Lab.Jilin- Shulan), neste grupo os neonatos foram sacrificados ao nascer; o grupo 2:composto por duas ratas prenhes, sendo que uma delas tomou água e a outra $100 \mathrm{ml}$ água com $21,5 \mathrm{mg} / \mathrm{kg}$ de cafeína, neste grupo os neonatos/ lactantes, foram sacrificados no $14^{\circ}$ dia; o grupo 3 : também composto por duas ratas prenhes, sendo que uma delas tomou água e a outra $100 \mathrm{ml}$ água com $21,5 \mathrm{mg} / \mathrm{kg}$ de cafeína, neste grupo os neonatos/ lactantes, foram sacrificados no $21^{\circ}$ dia.

Desta forma no grupo: 1 as ratas ingeriram uma média de 237,6 mg de cafeína durante 21 dias de acordo com seu peso diário; no grupo: 2 as ratas ingeriram 269,1 mg de cafeína durante 35 dias, ou seja, 21 dias de prenhez e 14 dias de amamentação; o grupo: 3 as ratas ingeriram 239,7 mg de cafeína durante 42 dias, nos 21 dias de prenhez e os 21 dias de amamentação, portanto todos os grupos receberam doses subagudas de cafeína.

As variáveis analisadas foram: a massa corporal relativa dos neonatos dos grupos 1,2 e 3, segundo a fórmula:

$$
\text { Massa corporal relativa }(\%)=\frac{\text { massa corporal diária }(\mathrm{g})}{\text { massa corporal dia nacimento }(\mathrm{g})} \times 100
$$

Os neonatos também eram contados, medidos, avaliados macroscopicamente e fotografados, para detectar qualquer anomalia macroscópica.

Após o sacrifício dos neonatos seguindo seus respectivos grupos: ao nascer, aos 14 dias e aos 21 dias de amamentação, foram isolados e pesados os seguintes órgãos: fígado e pulmão para comparar a massa relativa de cada órgão dos dois grupos (controle e tratado), segundo a fórmula:

$$
\text { Massa relativa do órgão }(\%)=\frac{\text { massa do órgão }(\mathrm{g})}{\text { massa corporal }(\mathrm{g})} \times 100
$$


Os órgãos retirados foram fixados para os procedimentos histológicos de rotina. O sacrifício dos animais, seguiu as normas do Comitê de Ética Animal (CEpan) do Centro Universitário "Barão de Mauá".

Os dados obtidos das variáveis analisadas foram submetidos ao teste de normalidade KolmogorovSmirnov (que acusou não -normalidade) e foram avaliados estatisticamente utilizando o teste não paramétrico Mann-Whitney (por se tratarem de amostras pequenas, $\mathrm{n}<30$, comparadas aos pares) e as diferenças foram consideradas significativas sempre que $\mathrm{p}<0,05$, utilizando 1 asterisco (*) para $\mathrm{p}<0,05,2$ asteriscos $(* *)$ para $\mathrm{p}<0,01$ e 3 asteriscos $(* * *)$ para $\mathrm{p}<0,001$.

\section{3-Resultados}

\section{1- Índice dos recém-nascidos}

A cafeína não alterou o índice de fetos das ratas tratadas em comparação ao controle, foram avaliadas a vitalidade, alterações macroscópicas externas e proporção de machos e fêmeas sacrificadas ao $14^{\circ}$ e $21^{\circ}$ dias (tab. 1 ).

\begin{tabular}{|l|l|l|}
\hline Variáveis & Controle & Tratado \\
\hline $\mathrm{N}^{\circ}$ de ratas & 03 & 03 \\
\hline $\mathrm{N}^{\circ}$ de Filhotes & 40 & 38 \\
\hline Alterações Macroscópicas & 0 & 1 \\
\hline Vitalidade & $100 \%$ & $94,73 \%$ \\
\hline $\begin{array}{l}\text { Proporção Macho/ Fêmea } \\
14^{\circ} \text { dias } \\
21^{\circ} \text { dias }\end{array}$ & $54 \% / 46 \%$ & $46 \%$ / 54\% \\
\hline \hline $\begin{array}{l}\text { Tabela 1: Índice dos fetos das ratas do grupo } \\
\text { controle e tratado. }\end{array}$
\end{tabular}

A massa corporal dos filhotes ao nascer não apresentou diferença estatisticamente significativa $(\mathrm{p}=0,6839)$ (fig.2) 


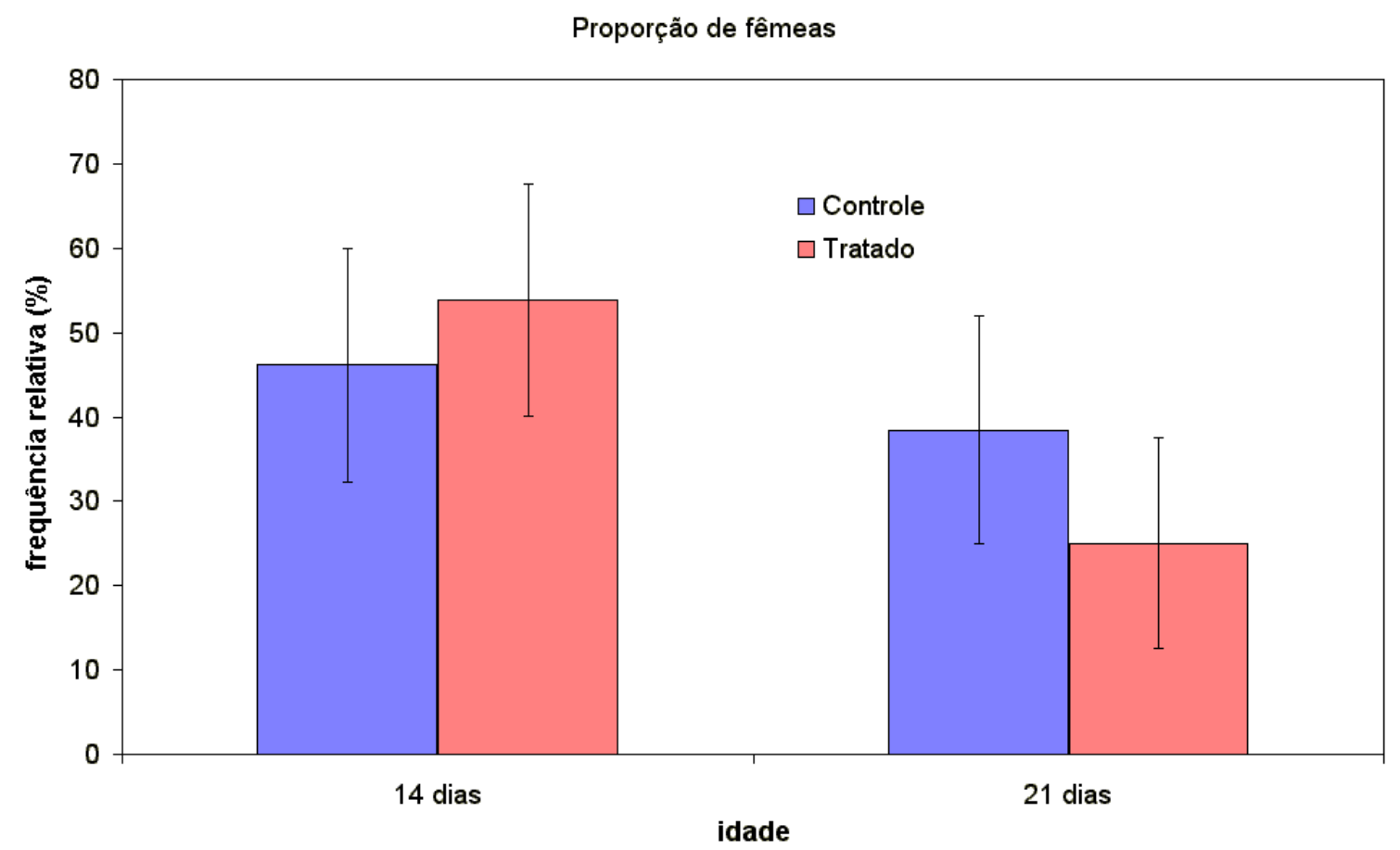

Fig.1 - Gráfico indicando a frequência relativa (\%) de fêmeas sacrificadas ao $14^{\circ}$ e $21^{\circ}$ dia de amamentação.

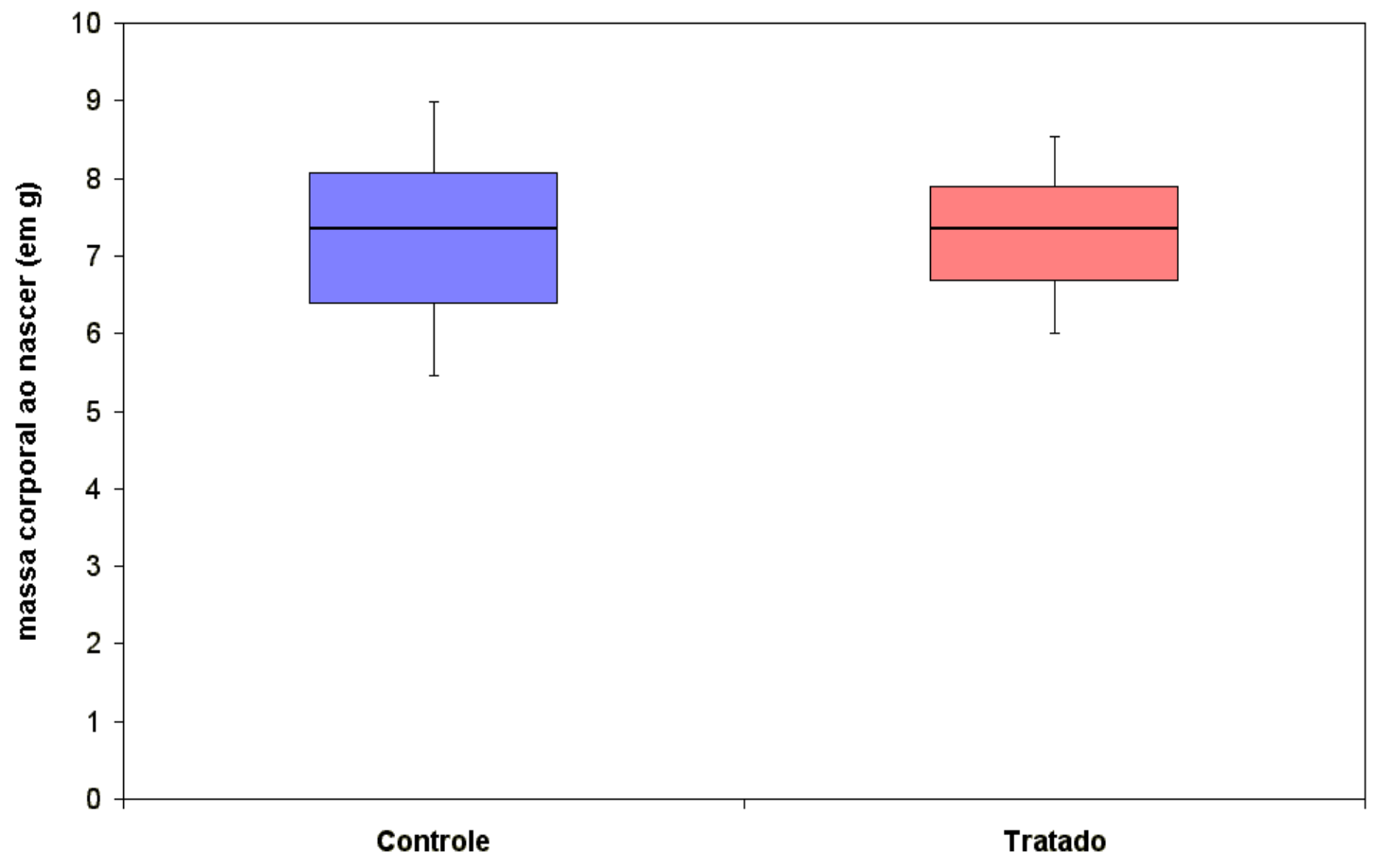

Fig. 2 : Gráfico indicando a massa corporal(g) após o nascimento 
Foi aplicado o teste não paramétrico Mann-Whitney para comparar as massas corporais dos filhotes sacrificados no $14^{\circ}$ dia entre os grupos controle e tratado, obtendo-se diferença estatística significativa em todos os dias de mensuração, porém observou-se que, até o $4^{\circ}$ dia, o controle apresentou uma média maior do que tratado, e do $8^{\circ}$ dia em diante, houve uma inversão na diferença: a média do grupo tratado foi maior do que a do grupo controle (fig.3)

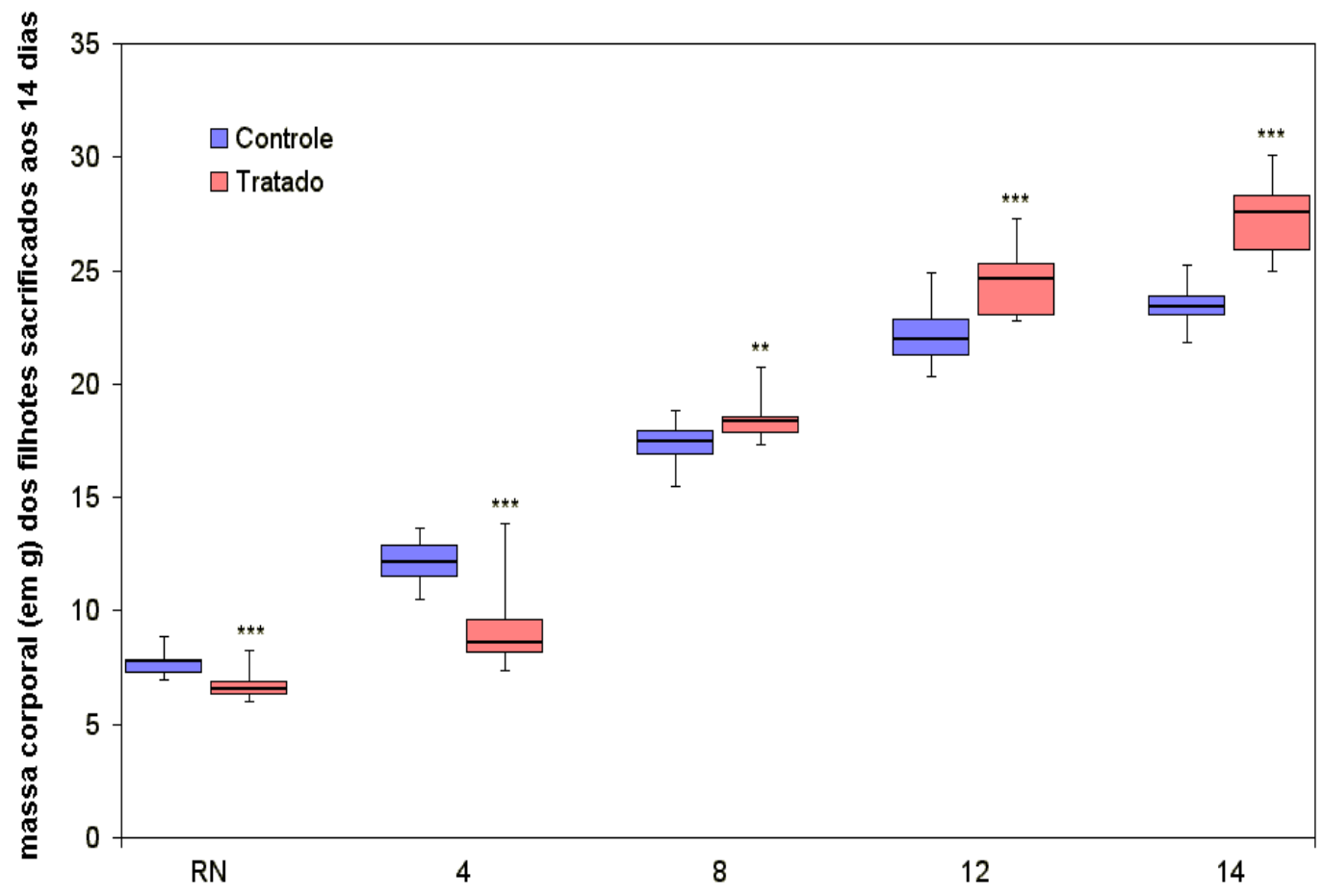

Fig.3: Massa corporal dos filhotes sacrificados no $14^{\circ}$ dia de amamentação.

Os animais sacrificados ao $21^{\circ}$ foi aplicado um teste não paramétrico Mann-Whitney, indicando diferença estatística significativa entre os grupos até o $7^{\circ}$ dia, onde o controle também apresentou uma média maior do que o tratado, esse média voltou a ser estatisticamente significativa no $16^{\circ}$ dia (fig.4).

Não temos como avaliar essas alterações ocorridas ao longo do período analisado, pois, a balança utilizada para essas pesagens era calibrada periodicamente, as pesagens ocorriam sempre no mesmo período do dia e a alimentação se manteve a mesma durante todo o experimento. 


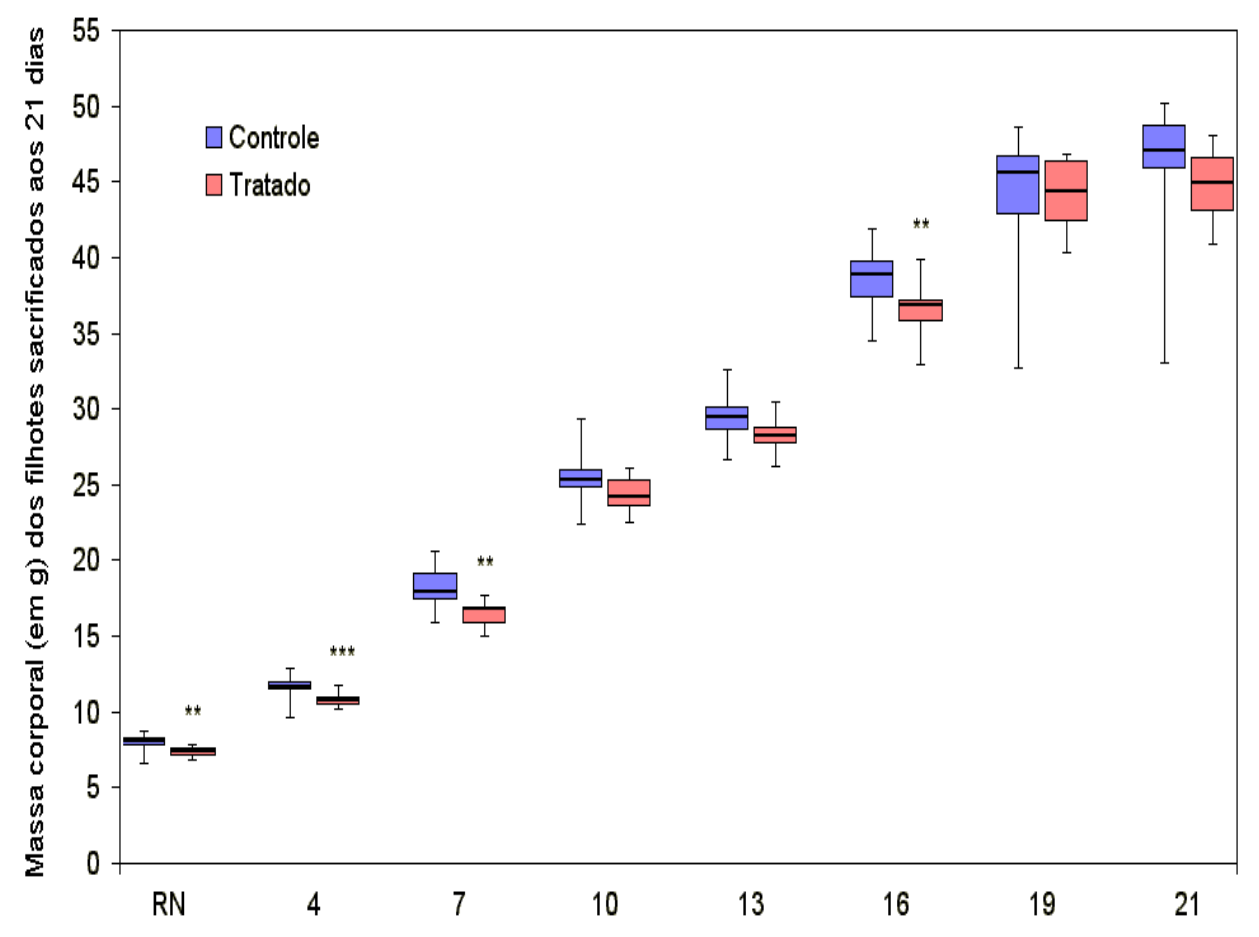

Fig.4: Massa corporal dos filhotes sacrificados no $21^{\circ}$ dia de

\section{2- Massa relativa dos órgãos}

A massa relativa dos órgãos foram analisadas e relacionadas a massa corporal de cada animal. Os órgãos analisados foram pulmão e fígado e foram observadas diferenças estatística significativa com mostram as Fig. 5 e 6.

No pulmão dos animais tratados com cafeína também obtivemos menor massa corporal relativa do nascimento até o $21^{\circ}$ dia de amamentação, com diferença estatística significativa $(\mathrm{p}<0,005)$ no $14^{\circ}$ dia de amamentação. 


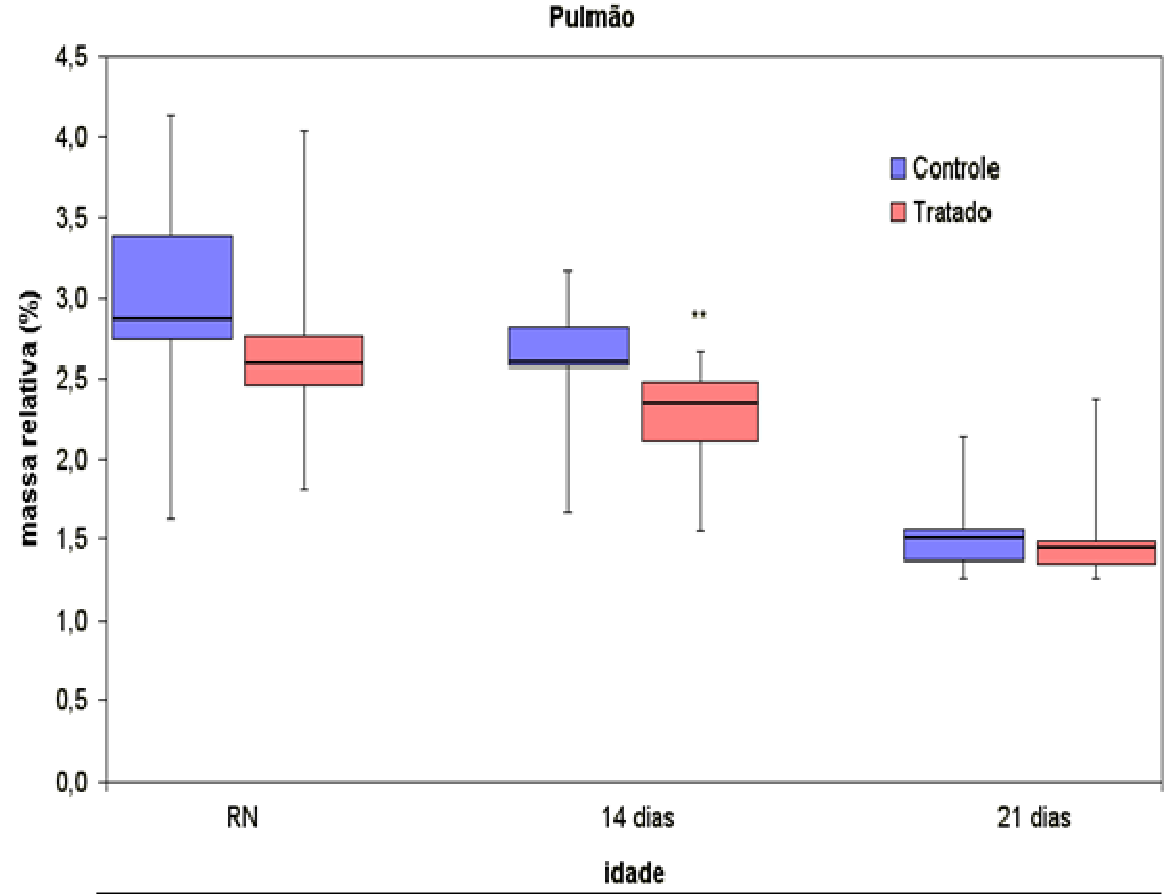

Fig. 5: Gráfico indicando a massa relativa do pulmão dos animais sacrificados ao nascer e nos $14^{\circ}$ e $21^{\circ}$ dias de amamentação

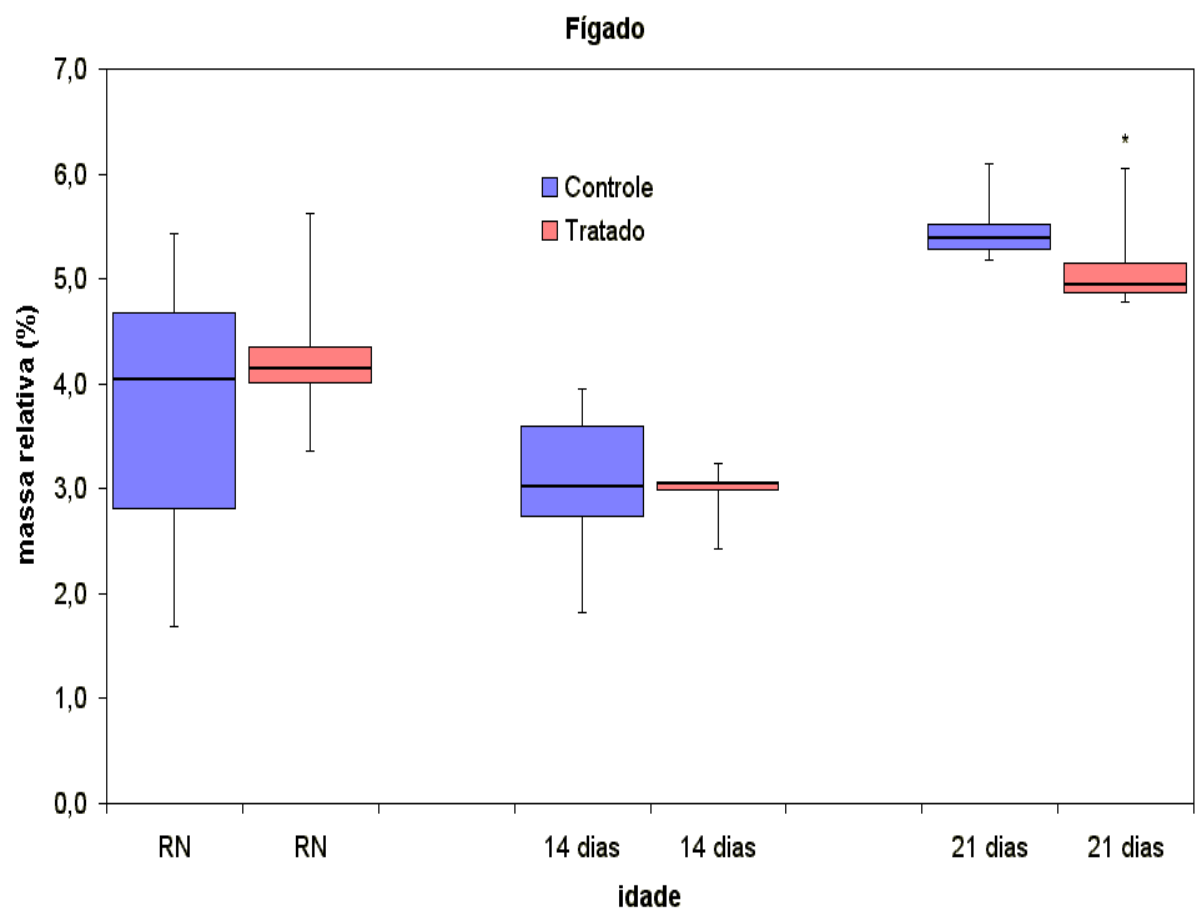

Fig. 6: Gráfico indicando a massa relativa do fígado dos animais sacrificados ao nascer e nos $14^{\circ}$ e $21^{\circ}$ dias de amamentação. 


\section{3-Comprimentos dos filhotes após o nascimento}

O comprimento dos filhotes cujas mães foram tratadas com cafeína, foi menor em relação ao grupo cujas mães tomaram somente água, foram medidos após o nascimento apresentaram diferença estatística significativa ( $\mathrm{p}=0,0064)$ e (Fig.7).

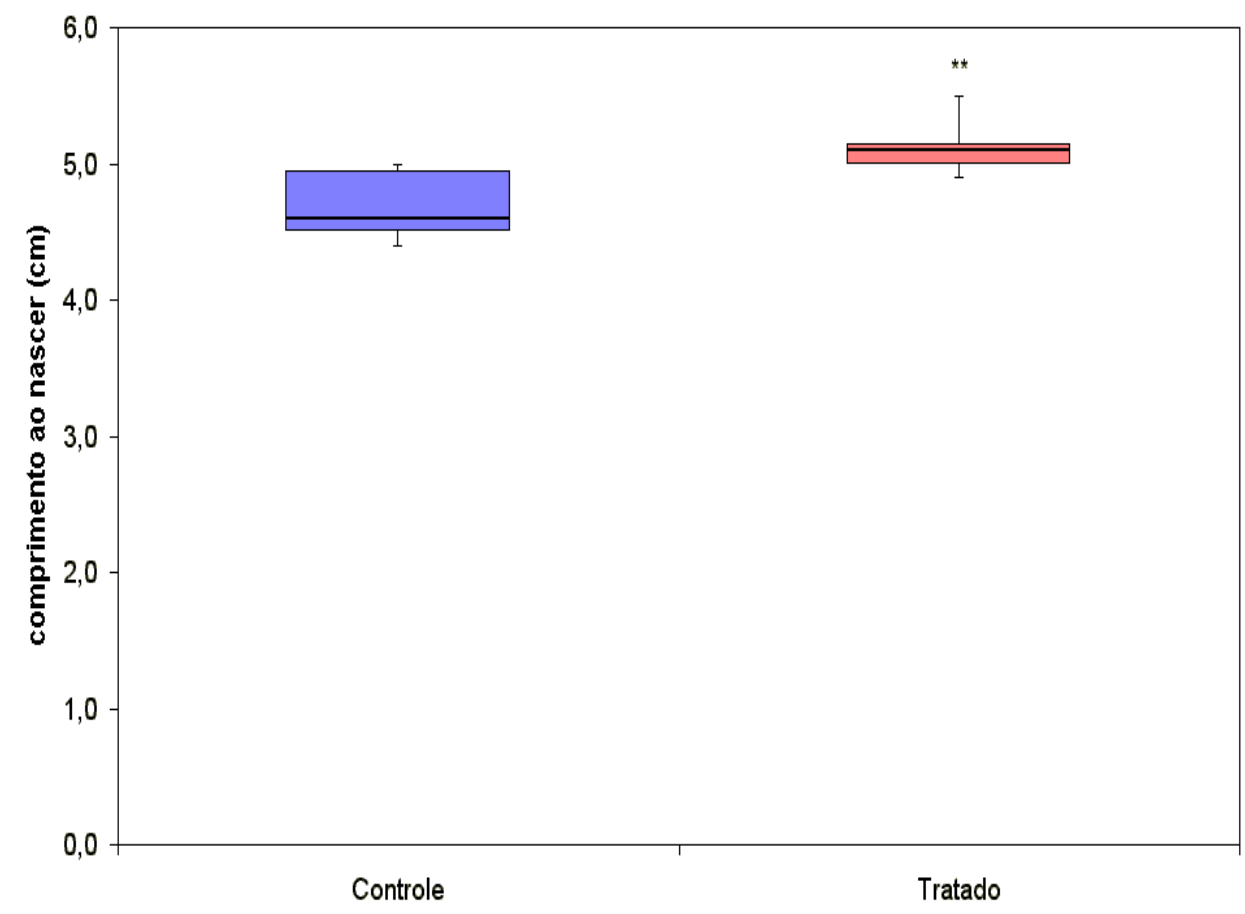

Fig.7: Gráfico indicando o comprimento $(\mathrm{cm})$ dos filhotes dos dois grupos após o nascimento 

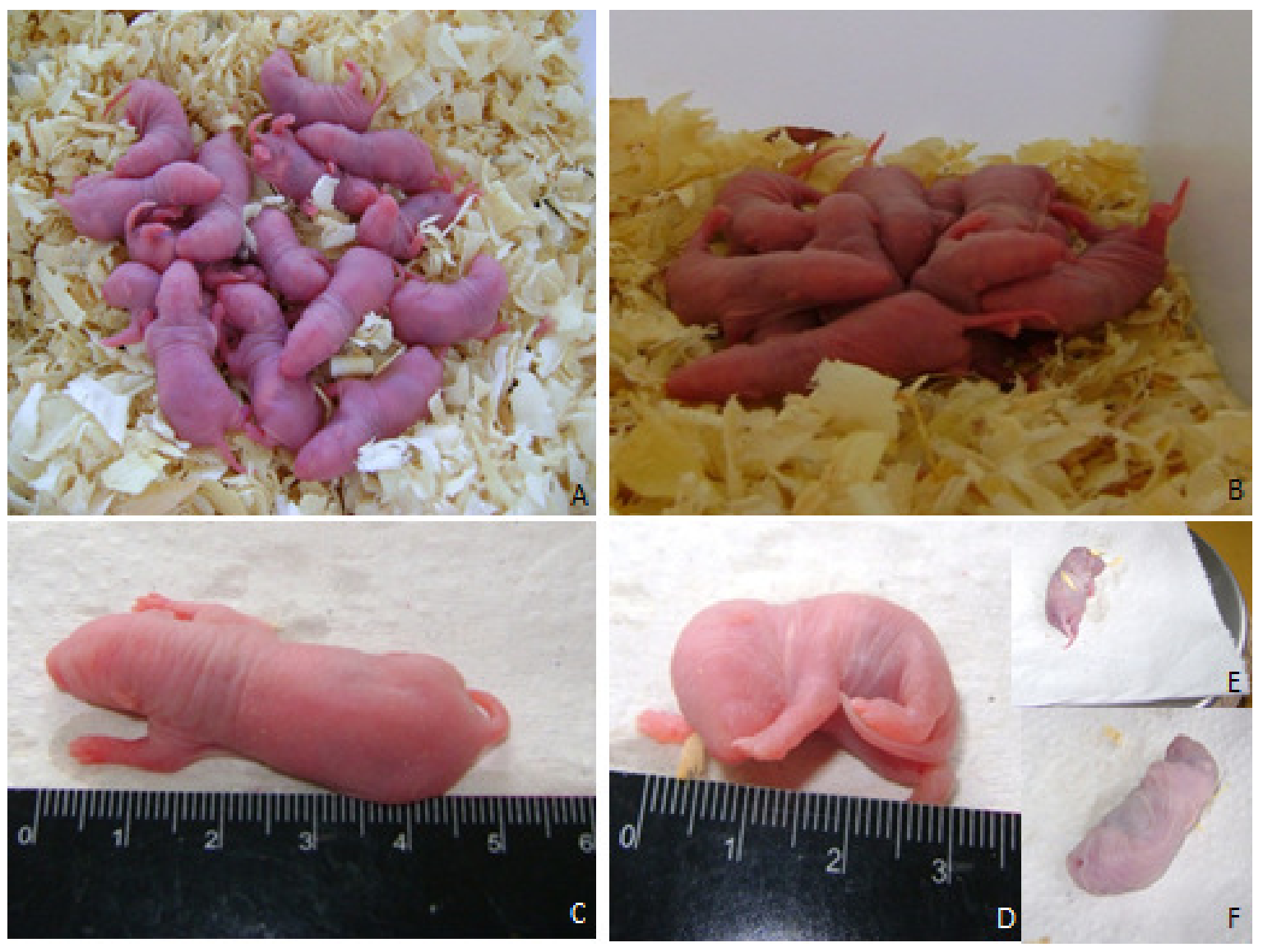

Fig.8: Fotografia dos filhotes. Em A: ninhada do grupo controle, Em B: ninhada do grupo tratado. Em C: medida $(\mathrm{cm})$ do filhote do grupo controle. Em D: medida $(\mathrm{cm})$ do filhote do grupo tratado. Em E: filhote natimorto do grupo tratado. Em F: anormalidades nos membros do filhote do grupo tratado

\section{5- Alterações histológicas}

$\mathrm{Na}$ análise histopatológica do fígado dos animais nascidos de mães que ingeriram cafeína durante todo período de gestação e amamentação e sacrificados após o nascimento observou-se nos hepatócitos, a presença de vacúolos citoplasmáticos (fig.9B) e núcleos mais volumosos e entre eles a presença de neutrófilos e sinusóides mais dilatados e repletos de sangue.

$\mathrm{Na}$ análise histopatológica do pulmão dos animais nascidos de mães que ingeriram cafeína durante todo período de gestação e amamentação e sacrificados após o nascimento observou-se uma proliferação celular resultando em um espessamento dos septos interalveolares com algumas hemácias no interior dos alvéolos (fig.9D). 

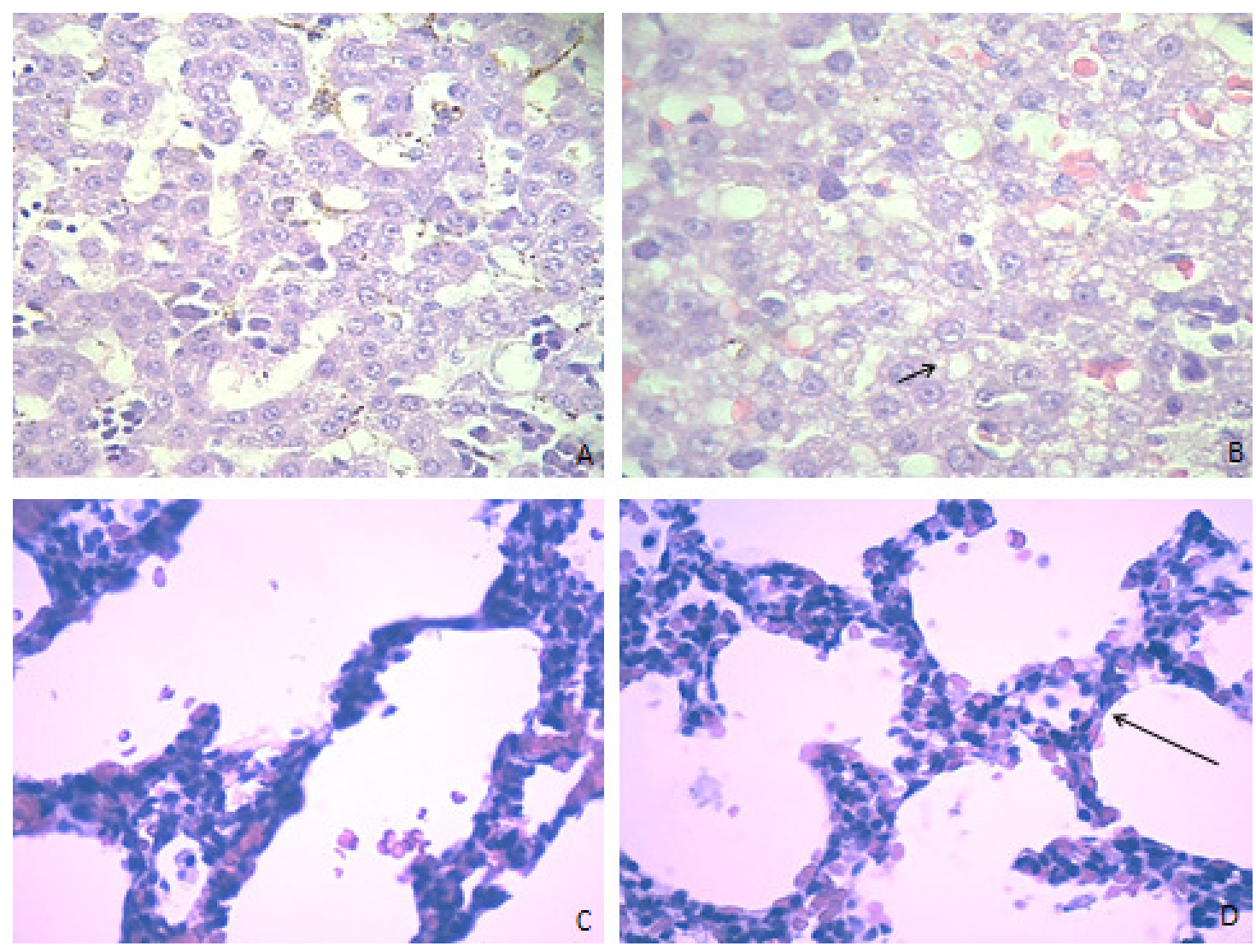

Fig. 9: Fotomicrografias dos aspectos histopatológicos do fígado e pulmão dos animais sacrificados após o nascimento (H.E.). Em A e C grupo controle que ingeriu água. Em B e D grupo tratado com cafeína. Presença de vacúolos citoplasmáticos (seta curta) e espessamento dos septos interalveolares e hemácias (seta longa). Aumento final: 100X e $400 X$.

A histopatologia dos hepatócitos de animais sacrificados após 14 dias de amamentação apresentou-se com um citoplasma de aspecto diluído e bem indistinto, caracterizando uma tumefação celular. A megalocitose caracterizou-se pela presença de megalócitos, que são hepatócitos apresentando gigantismo nuclear e citoplasmático (fig.10B). Não se observou no grupo controle o citoplasma com essas alterações de forma tão acentuada (fig.10A).

No pulmão de animais sacrificados após 14 dias de amamentação observou-se um espessamento celular nos septos interalveolares com núcleos mais densos ao redor dos alvéolos e um denso infiltrado inflamatório (fig.10D), alterações não encontradas nos animais que ingeriram água sem cafeína(fig.10C). 


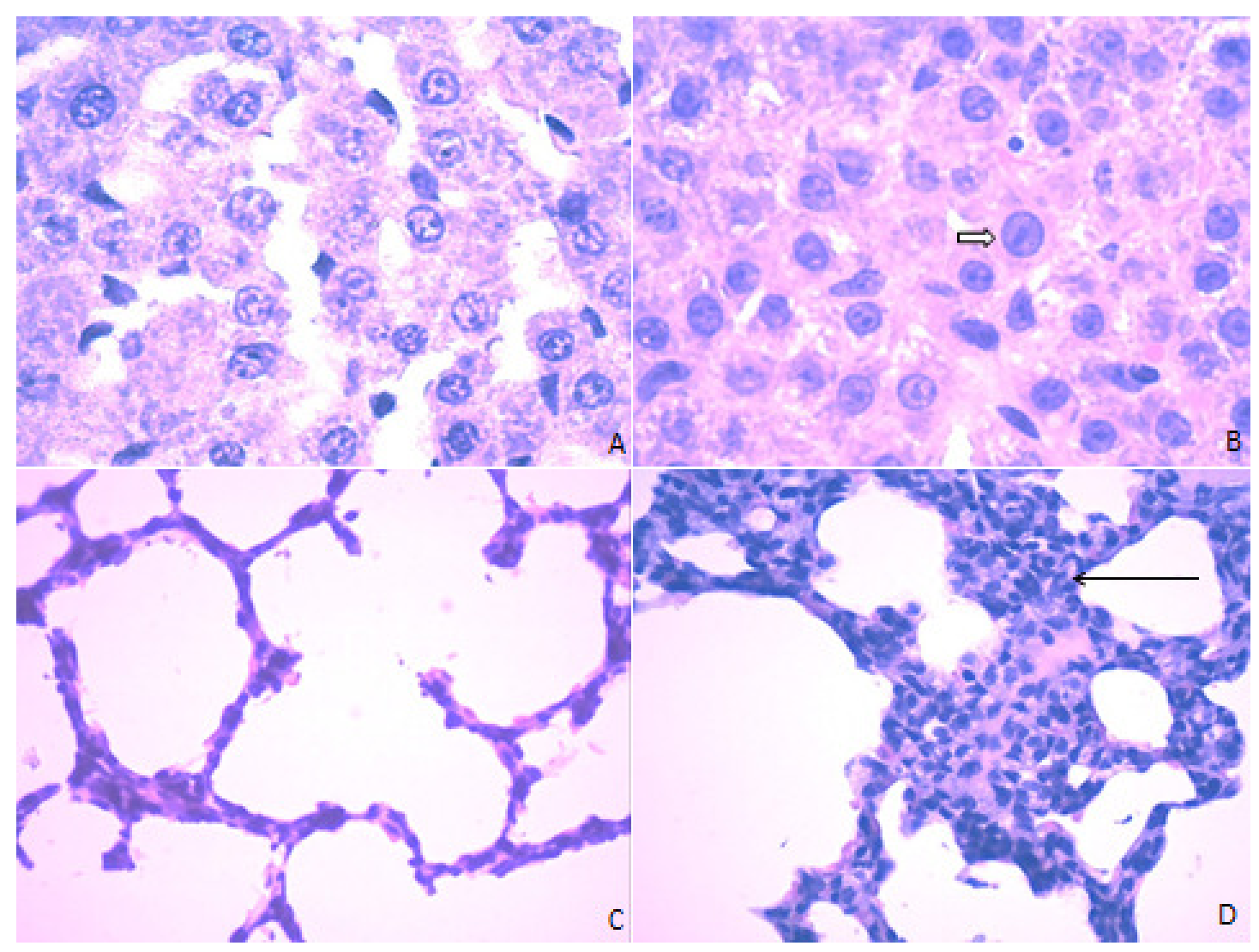

Fig. 10: Fotomicrografiasdos aspectos histopatológicos do fígado e pulmão dos animais sacrificados aos 14 dias (H.E.). Em A e C grupo controle que ingeriu água. Em B e D grupo tratado com cafeína. Presença de megalócitos (seta cheia) e espessamento dos septos interalveolares e infiltrado inflamatório (seta longa). Aumento final: 400X e 100X.

Após 21 dias de amamentação os animais foram sacrificados e observou-se na histopatologia do fígado uma moderada megalocitose (fig.11B) caracterizando uma intoxicação pela cafeína; não é possível observar qualquer alteração na morfologia do fígado dos animais que não ingeriram cafeína (fig. 11A).

Assim como no pulmão, acentua-se o espessamento do septo interalveolar e a presença de infiltrado inflamatório (fig.11D). Enquanto nos animais que não ingeriram cafeína observa-se uma histoarquitetura do parênquima pulmonar preservadas, sem alterações aparentes. 


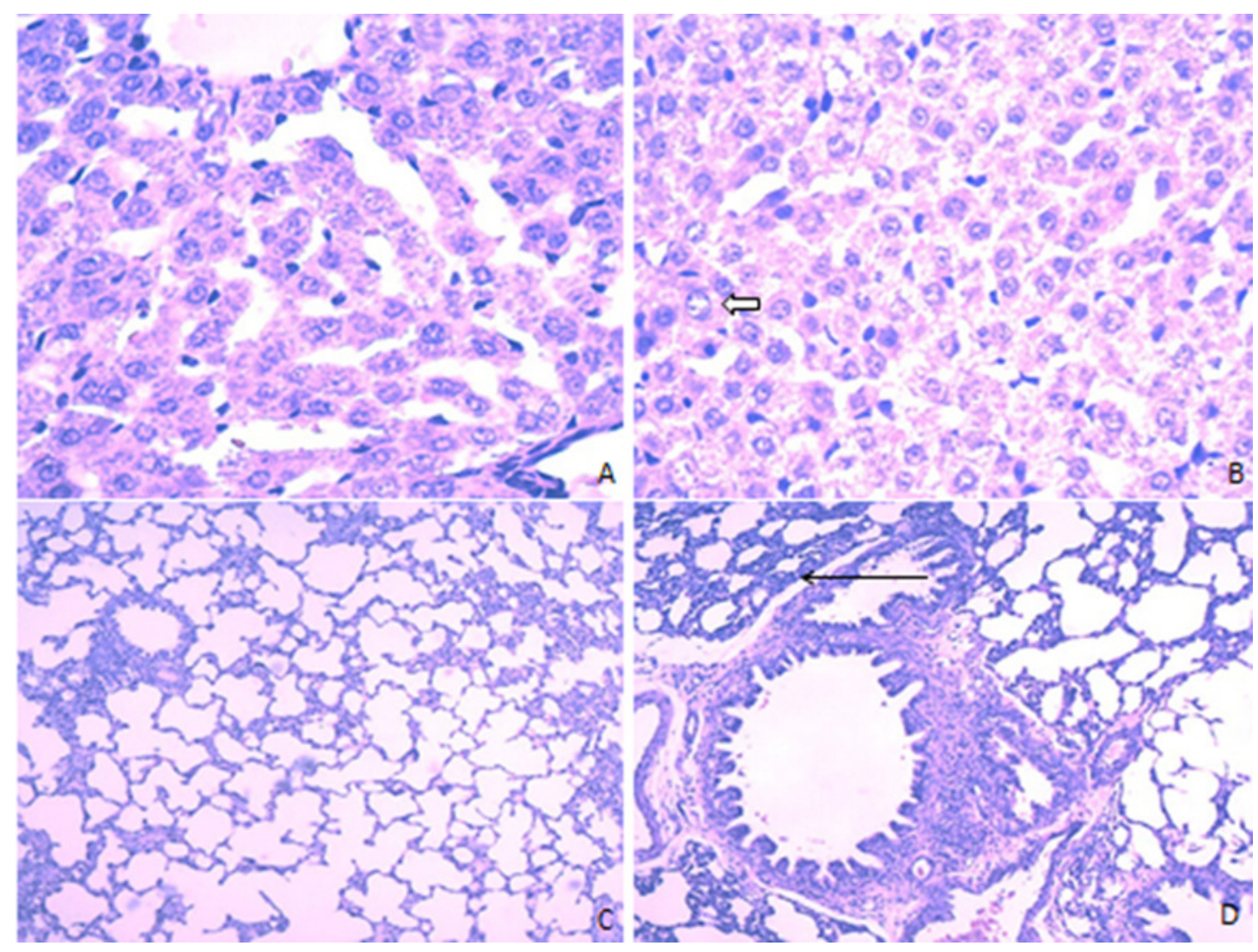

Fig. 11: Fotomicrografias dos aspectos histopatológicos do fígado e pulmão dos animais sacrificados aos 21 dias (H.E.). Em A e C grupo controle que ingeriu água. Em B e D grupo tratado com cafeína. Presença de megalócitos (seta cheia) e espessamento dos septos interalveolares (seta longa). Aumento final: 100X.

\section{4- Discussão}

Atualmente a equipe de saúde deve estar empenhada em promover a amamentação como o meio mais seguro para garantir a nutrição mais adequada do recém nascido; sendo assim, percebe-se como indispensável, a relevância de uma adequada formação e capacitação técnica dos profissionais de saúde, através de cursos de pós-graduação e especializações, de forma a enriquecer informações e conhecimentos, competências e principalmente motivações necessárias para incentivar, promover e apoiar o aleitamento materno (ALMEIDA, 2004).

Considera-se tanto na gestante quanto na parturiente a importância de conhecer os diversos tipos de alimentos consumidos assim como suas diversas funções no organismo.

Nenhum componente da alimentação possui todos os nutrientes que atendam as necessidades do organismo, desta forma é importante uma dieta adequada para se conquistar uma boa saúde.

Sendo assim, a exposição a alguns dos fatores de risco podem ser previsíveis por programas de saúde direcionados à mulher, evitando que essa condição propicie maior morbidade e mortalidade de neonatais (BICALHO, 2002). 
Segundo Chaves (2004), o principio fundamental da prescrição de medicamentos para mães em lactação baseia-se principalmente no conceito de risco e beneficio. As vantagens do aleitamento materno para a criança são enormes, enquanto os riscos da grande maioria dos medicamentos são mínimos, sendo que grande parte das informações sobre as drogas na lactação são baseadas em doses fixas e em estudos de curta duração.

De acordo com o mesmo autor, a amamentação ao seio somente deverá ser interrompida ou desencorajada se existir evidência substancial de que a droga usada pela mãe poderá ser nociva para a criança, ou quando não houver informações a respeito e a droga não puder ser substituída por outra que seja inócua para o bebê. Em geral, mães em amamentação devem evitar o uso de medicamentos. No entanto, se isto for imperativo, deve-se fazer opção por uma droga já estudada, que seja pouco excretada no leite materno, ou que não tenha risco aparente para a saúde da criança. Selecionando drogas sabidamente seguras e levando-se em conta a idade do lactente, o aleitamento materno só excepcionalmente precisará ser desencorajado ou descontinuado quando a mãe necessita de tratamento farmacológico.

Neste estudo procurou-se demonstrar possíveis alterações provocadas pelo uso abusivo da cafeína no período de gestação e lactação, definindo a dose utilizada com uma projeção do teor de cafeína nos alimentos e drogas que seriam mais utilizadas continuamente por esses pacientes.

O rato foi o modelo experimental escolhido por ser de fácil manutenção e manuseio, e por se conhecer bem as particularidades desse animal como: características reprodutivas, período de gestação, período de amamentação parâmetros fundamentais para realização desta pesquisa.

A administração de cafeína em dose equivalente a 4-5 xícaras de café durante o período gestacional e lactacional pode causar alterações no peso dos filhotes que aparecem no desmame (FIOREZE, 2011), esses resultados se coadunam com aqueles que verificamos ao $21^{\circ}$ dia de amamentação, uma perda de massa corporal (fig. 4).

Segundo Bicalho (2002), a cafeína atravessa pela placenta e durante o período fetal, há falta de enzimas necessárias para a demetilação, que produz diversos efeitos que podem influenciar o crescimento do feto, como encontramos com diferença estatística significativa (fig 7).

A cafeína é uma substância absorvida de modo rápido e eficiente, via administração oral, através do trato gastrointestinal com aproximadamente $100 \%$ de biodisponibilidade, alcançando um pico de concentração máxima na corrente sanguínea após 15 a 120 minutos de sua ingestão (SINCLAIR e GEIGER, 2000), em nosso experimento a cafeína foi administrada em doses subagudas por via oral, diluída em água de beber.

Segundo Altimari (2001), os níveis de absorção de cafeína são similares quando da ingestão oral de bebidas, cápsulas ou barras de chocolate. Entretanto uma possível variação na velocidade de absorção pode ser determinada principalmente pela ocupação gástrica.

Encontrou-se no exame histopatológico do fígado dos animais tratados com cafeína uma moderada megalocitose com todas as suas particularidades, indicativo de uma intoxicação pela cafeína, em concordância com Matuoka et al (2007), que em uma análise histomorfométrica de fígado de ratos, apontou hepatócitos maiores, diâmetros nucleares aumentados, menor número de núcleos por área e grande quantidade de vacúolos intracitoplasmáticos; quando comparados aos controles que não ingeriram café.

O fígado de ratas que ingeriram $50 \mathrm{mg} /$ dia de café durante 30 dias e depois durante todo acasalamento e prenhez apresentou congestionamento e dilatação vascular e, consequentemente, a desorganização do espaço porta e degeneração intracelular; o que confirma 
o fígado como a principal rota de eliminação de cafeína e outras metilxantinas ( MATUOKA et al, 2007).

De acordo com Chaves (2004), durante os primeiros dias de lactação (colostro), as células alveolares são pequenas e o espaço intercelular é largo, o que faz com que substâncias maternas, incluindo drogas, linfócitos, imunoglobulinas e proteínas transferem-se mais facilmente para o leite materno, a megalocitose encontrada é indício de que a cafeína passou para o leite no $14^{\circ}$ e $21^{\circ}$ dias de amamentação onde foram observados os hepatócitos com megalocitose.

Segundo Capelozzi (2004), os pulmões tem importante função na metabolização e remoção de substâncias endógenas presentes na corrente sanguínea, considerando este fato é importante notar a possibilidade de toxicidade pulmonar e alterações na permeabilidade da membrana alvéolo capilares causadas por diversos tipos de substâncias, em nossos achados encontramos um espessamento do septo interalveolar mais acentuado nos animais tratados com cafeína quando comparados com os animais que ingeriram somente água, que mantiveram preservadas a histoarquitetura do parênquima pulmonar.

Nossos resultados nos encorajam a continuar com outras investigações, que possam definir outras doses, outras formas de administração e os seus efeitos em ratas prenhas e em período de amamentação; a fim de extrapolar para humanos, podendo desta maneira contribuir para o beneficio da saúde de gestantes e lactentes.

\section{5- Conclusão}

Os resultados de nosso modelo experimental demonstram que a cafeína administrada na dose de $21,5 \mathrm{mg} / \mathrm{kg}$ de massa corporal, nos períodos estipulados, causou:

- Diminuição de massa corporal dos filhotes pelo menos até os 16 primeiros dias de amamentação;

- $\quad$ Diminuição do comprimento dos filhotes;

- $\quad$ Diminuição da massa relativa de órgãos;

Esses resultados corroboram com aqueles encontrados na literatura que se referem aos efeitos da cafeína em humanos; aqui reproduzidos de maneira experimental.

O modelo sugere ainda alterações histopatológicas hepática como: megalocitose e dilatação de vasos sanguíneos; e alterações histopatológicas pulmonares como: infiltrado inflamatório e espessamento de septo interalveolar.

Ao se considerar necessário, no âmbito das estratégias de incentivo, a educação permanente dos profissionais de saúde; este trabalho contribui para uma orientação mais criteriosa desses profissionais em relação a alimentos e drogas que possam conter doses mais elevadas de cafeína em pacientes gestantes, lactantes e neonatos. 


\section{6- REFERÊNCIAS BIBLIOGRÁFICAS}

ALMEIDA, L.C.; BARACHO, E.L.L.S., Fisioterapia Aplicada à Obstetrícia: Alterações do sistema músculo-esquelético e suas implicações. Cap.3, 2ed. Rio de Janeiro: Medse Editora Médica e científica Ltda. 2002.

ALTIMARI,L.R, et. al. Cafeína: ergogênico nutricional no esporte. Rev. Bras. Ciên. e Mov. Brasília v. 9 n. 3 p.57 -64, 2001.

BICALHO, G.G. e BARROS FILHO, A. de A. Peso ao nascer e influência do consumo de cafeína In: Rev. Saúde Pública vol.36 no.2 São Paulo. 2002.

BUDNEY, A.J.; HIGGINS, S.T.; HUGHES, J.R.; BICKEL,W.K. Nicotine and caffeine use in cocaine-dependent individuals. J. Subst. Abuse, Norwood, v.5, p.117-130,1993.

CAPELOZZI, A.M. Determinantes funcionais e morfológicos de ação de droga sobre os pulmões utilizando um modelo experimental em cobaias sob uso do cloridrato de fluoxetina: Uma Reflexão. 114p. Tese ( Doutor em Ciências). Faculdade de Medicina da Universidade de São Paulo, São Paulo- SP .2004.

CARBONARI, SOLANGE BARROS; SAMPAIO, MAGDA M. S. CARNEIRO-. COMPOSIÇÃO DO LEITE HUMANO: ASPECTOS IMUNOLOGICOS. In: REGO, Jose Dias. ALEITAMENTO MATERNO. 2. ed. São Paulo: Atheneu, 2006. Cap. 6, p. 104-105.

CHAVES G. R. e LAMONIER A. J. Uso de medicamentos durante a lactação In: J. Pediatr. (Rio J.) vol.80 no.5 supl. Porto Alegre Nov. 2004

FIOREZE, G.T; ARDAIS, A.P; MIORANZZA S; PORCIÚNCULA L.O. Administração de cafeína durante o período gestacional e lactacional em ratas fêmeas altera o número de implantações embrionárias e o peso dos filhotes. In: Universidade Federal de Ciências da Saúde de Porto Alegre Laboratório de Estudos sobre o Sistema Purinérgico, Departamento de Bioquímica - Universidade Federal do Rio Grande do Sul. 2011.

FISONE G, BORGKVIST A, USIELLO A.. Caffeine as a psychomotor stimulant: mechanism of action. In: Cell Mol Life Sci. 61; 2004 Apr; 857-872

KOZLOWSKI, L.T.; HENNINGFIELD, J.E.; KEENAN, R.M.; LEI, H.; LEIGH, G.; JELINEK, L.C.; POPE, M.A.; HAERTZEN, C.A. Patterns of alcohol, cigarette, and caffeine and other drug use in two drug abusing populations. J. Subst. Abuse Treat., New York, v.10,p.171-179, 1993.

MANDEI, H.G.. Update on caffeine concumption, disposition and action. In Food and Chemical Toxicology. 2002. 1231-1234

Persp. online: biol. \& saúde, Campos dos Goytacazes, 10 (3), 44-61, 2013 60 
MATUOKA, R.I., VIEIRA, B.B., CAMPOS, A.A.,BRENTEGANI,L.G.,LACERDA, S.A. InvestigaçãoRevista Científica da Universidade de Franca. v. 7 n. 1/3 jan. / dez. 2007 p. 103-108.

PENILDON, SILVA, Farmacologia, 8ed. Rio de Janeiro: Guanabara Koogan, 2010.1352p.

RACHIMA-MAOZ, C.; PELEG, E.; ROSENTHAL, T.The effects of caffeine on ambulatory blood pressure in hypertensive patients. American Journal of Hypertension, v.11, p.1426-32, 1998.

SINCLAIR, C.J.D.; GEIGER, J.D. Caffeine use in sport: a pharmacological review. Journal of Sports Medicine and Physical Fitness, v.40, n.1, p.71-9,2000.

SOUZA, R. A. G. DE; SICHIERI, R. Consumo de cafeína e prematuridade, Rev. Nutr: 18 (5):643650 , set-out.2005.

RICCI, S. S. Enfermagem materno - neonatal e saúde da mulher. Rio de Janeiro: Guanaba Koogan, 2008.736p.

SINCLAIR, C.J.D. e GEIGER, J.D. Caffeine use in sport: a pharmacological review. J. Sports Med. Phys.Fitness, 40(1): 71-79, 2000.

SOUZA, R. A. G. DE; SICHIERI, R. Consumo de cafeína e prematuridade. Rev. Nutr: 18 (5): 643650, set-out, 2005.

REMIÃO, F. Trabalho realizado no âmbito da disciplina de Toxicologia e Análises Toxicológicas I. Faculdade de Farmácia da Universidade do Porto, p. 3, 2004.

SOUZA, R. A. G.; SICHIERI, R.; Consumo de cafeína e prematuridade. Rev. Nutr. v.18 n.5 Campinas set./out. 2005. Disponível em <http://www.scielo.br> Acesso dia 01 de agosto de 2006.

SPRIET, L.L. Caffeine and performance. International Journal of Sport Nutrition, v.5, p.84-99, 1995.

STRAIN, E.C. GRIFFTHS, R.R. Caffeine related disorders. In: SadockBj; Sadock VA. Textbook of Psychiatry, 7ed. Baltimore: Lippincott, 2000.

YAMADA, Y.; NAKAZATO, Y.; OHGA, A. The mode of action of caffeine on catecholamine release from perfused adrenal glands of cat. British Journal of Pharmacology, v.98, n.2, p.351-6, 1989. 